\title{
Aggregation and Divisibility of Damage in ENGLAND AND WALES: INSURANCE
}

Richard Lewis

\section{Introduction}

This report has both a more limited and a wider focus than many of the others in this collection. It is narrower because it examines only the insurance aspects of the various causation and other issues highlighted by the research project. That is, it only deals with the matters raised in part IV of the Questionnaire. However, it is wider in that it forms part of a much larger study of the relationship between insurance and the tort system. ${ }^{1}$ In that study insurance is described as providing the "lifeblood" of the law of tort. Although the influence of insurance upon the common law rules is only partial, insurers are of vital importance to the system of compensation for personal injury as a whole. They administer the system and exercise considerable control over it. Without them the importance of tort law would be very much diminished.

Although this report is limited to the law of England and Wales, it also makes occasional reference to the position in the USA because judges in the UK have drawn comparisons with that jurisdiction, and there has been much more litigation in that country on the issues highlighted here. One difference between the two countries, however, is that the position in the UK is more complicated because insurers have not adopted standard wording as they have in the USA, for example, in relation to general liability policies. There are no standard form words universally used in insurance policies for United Kingdom risks.

As a preliminary matter it is important to note that it is not possible to answer with confidence or in detail several of the questions posed by the Question-

\footnotetext{
See the present author's previous contributions: $R$. Lewis in: G. Wagner, Tort Law and Liability Insurance (2005) at 47 ff.; Insurance and the Tort System (2005) 25 (1) Legal Studies 85 ff.; Insurers and Personal Injury Litigation: Acknowledging the "Elephant in the Living Room" (2005) J Personal Injury Law 1-11; How Important are Insurers in Compensating Claims for Personal Injury in the UK? (2006) 31 (2) Geneva Papers on Risk and Insurance $323 \mathrm{ff}$. A revised version of the latter article appeared in booklets published by Munich Re, How to Better React to Developments in Liability Insurance (2006) 76 ff.; Risk Liability and Insurance: Tort Law and Liability Insurance (2007) $29 \mathrm{ff}$.
} 
naire relating to the actual practice of insurers. This is because there has been little empirical examination of the common practice of insurers or how policies are construed on a day to day basis. Nor has there been much analysis of which form of policy wording predominates in the various forms of insurance. The literature instead concentrates upon judicial interpretation of specific clauses relevant to particular disputes, and this court-based approach to the analysis of insurance practice forms the foundation of the present report. It may not therefore always reflect current insurance practice.

4 A further complication is that it is very difficult to make statements that are applicable to all forms of insurance. As an example, the Questionnaire recognises the potential difference between compulsory liability insurances and those obtained voluntarily (see Question 43 infra no. 48). It is indeed the case that the rules relating to third-party liability where insurance may be compulsory differ from those applied to first party loss insurance. In addition, the wording in policies dealing with different varieties of first party cover may be particular to the individual insurances. A single insurer may use different words in different types of policy even though the clauses deal with similar, or even identical, issues. It is therefore not possible to provide clear answers which are applicable to all forms of insurance at all times.

\section{Specific Questions in Part IV of the Questionnaire}

\section{A. Caps and Deductibles}

35. In your national legal system, are there statutory principles or have the courts developed general principles that address the issue of whether a damage event is considered to be a single incident, in which case it is the insurer's overall liability that is limited by any applicable cap, or a plurality of several independent losses, in which case the cap applies to each, leaving the insurer to pay up to the specified sum for each one? Alternatively, is this issue addressed by standard clauses used in contracts of insurance?

5 In the UK there are no statutory principles but there are general principles which have been developed by the courts. There are clauses in insurance contracts which deal with the issues but there is no standard-form wording which universally is used.

6 Both this Question, and Question 37 below, focus upon whether the loss results from a single incident or a plurality, and this lies at the heart of the insurance section of the research project. Unfortunately the deceptively simple question cannot be met with a simple answer. It requires, first, close consideration of the specific words used in particular policies; and second, the application of what are very uncertain rules relating to causation. What therefore follows is an extensive analysis of the relevant principles relating to Questions 35 and 37. These principles are then used to suggest probable answers for the specific problems set in Questions 36 and 38. 
The difficulties that can arise in applying the relevant rules may be illustrated by reference to the typical words of a public liability policy:

"The insurer agrees to indemnify the Insured in respect of all sums which the Insured has become legally liable to pay as compensation for:

(a) accidental death of or accidental personal injury to any person (b) accidental loss of or accidental damage to material property occurring during the policy period."

The problems caused by potential multiple causes of damage can be illustrated by the difficulties the courts have experienced in construing the meaning of both "accidental" and "occurring" as used in the above wording. To what extent can an "accident," or an "event," or "occurrence" be found even though there are a number of elements which may have combined to cause the loss? In effect, as the Questionnaire asks, is there a single incident or a plurality?

\section{"Accident"}

An early attempt by insurers to avoid the complications caused by multiple causation of damage involves the use of the word "accidental" injury to distinguish damage caused by wear and tear, or injury resulting from disease or the natural ageing process. The latter are thought to be ten times more likely to be the cause of disability in the population compared to accidents causing personal injury. For some types of policy, therefore, insurers have been keen to limit the scope of their liability and to exclude gradual developments which cause loss or disability. Because the causal factors in disease cases are much harder to identify, the allocation of liability is much more uncertain. By contrast it is usually much clearer to identify the cause of injury and responsibility for it where an "accident" is involved.

Accident therefore became one of the first battlegrounds over which disputes concerning multiple causal factors were fought. Insurers specified "accident" in the hope of distinguishing losses caused gradually where there is no clear "trigger" upon which liability under a policy can be based. Slow, hidden, progressive damage is harder to identify, mitigate, and control. However, insurers' attempts to avoid such liabilities had only limited success.

An early setback for insurers was in the case of Hamlyn $v$ Crown Accidental Insurance Co Ltd. ${ }^{2}$ The claimant was insured for "any bodily injury caused by violent, accidental, external and visible means." No doubt the insurer had used this combination of words in an attempt to prevent any liability arising for internal hidden physiological changes. This was reinforced by a clause in the policy which excluded liability for injuries arising from "natural disease or weakness or exhaustion consequent upon disease." In spite of this, the company was held liable when the insured dislocated the cartilage in his knee when

${ }^{2}$ [1893] 1 Queen's Bench (QB) 750. 
bending over to pick up a marble. The fact he had suffered an internal injury did not prevent it being classified as an accident because the injury had been unexpected. The court treated the insured's bending over and stooping for the marble as external means.

12 Further difficulty was caused for insurers by courts interpreting "accident" differently depending upon whether claims were being made, for example, under the life insurance element of a travel policy, ${ }^{3}$ under a workers' compensation policy, ${ }^{4}$ or in seeking compensation under the Warsaw ${ }^{5}$ or Montreal ${ }^{6}$ Conventions. In some cases an accident has been held to have a very wide meaning indeed. It has even been held to encompass the situation where in fact a disease is suffered. This is because the accident is taken to occur at the point where the bacillus penetrates the skin to cause the infection - even though this infection may take some time to reveal itself. ${ }^{7}$ The artificial, but precise, point in time when the bacillus enters the body is sufficient to distinguish an "accident" from the gradual onset of illness which has no such trigger point.

13 To try to limit the court's discretion to find liability in such a case, insurers have sought to define further the meaning of "accident" so as to exclude disease. Similarly, in property damage policies accidental loss has been defined with the intention of limiting liability for the gradual infliction of damage over a period of time. The specific time, place and cause of the accident must be established. Even then a regularly occurring event has been held to result in liability, as where regular releases of chlorine gas were each found to be accidental after measures had been taken to prevent their re-occurrence. ${ }^{8}$

14 However, it is not always the case that insurers have sought to revise policy wording in order to limit their exposure. They have also allowed cover to expand to meet the needs of the marketplace. For example, by the 1960 s the use of "accident" in the standard liability policy in the USA was thought too restrictive for the market because it did not admit claims which were based on events which were not "sudden." This denied coverage, for example, where toxic chemicals leaked from a storage site over a long period of time. In order to meet demands for insurance in such circumstances the wording of the standard policy was changed from "accident" to "occurrence" with the intention that human error which led to continuous or repeated exposures and subsequent damage would be covered. The needs of those requiring insurance

\footnotetext{
${ }^{3}$ De Souza v Home \& Overseas Insurance Co Ltd [1995] Lloyd's Reinsurance Law Reports (LRLR) 453.

${ }^{4}$ Fenton v Thorley [1903] Appeal Cases (AC) 443.

${ }^{5}$ Deep Vein Thrombosis and Air Travel Group Litigation [2004] QB 234.

${ }^{6}$ Barclay v British Airways [2008] 1 Lloyd's Law Reports (Lloyd's Rep) 661.

7 Brintons $v$ Turvey [1905] AC 230. For a detailed examination see R. Lewis, Compensation For Industrial Injury (1987) $37 \mathrm{ff}$., and $i d$., What is an Accident? (1987) Northern Ireland Legal Quarterly 76.

${ }^{8}$ Australian Paper Manufacturers v American International Underwriters [1994] 1 Victorian Reports (VR) 685.
} 
against causing gradual environmental damage could then be met. This was followed by a third phase from about 1973 when insurers became more circumspect, particularly when underwriting pollution coverage. ${ }^{9}$ In the UK, although the wording of policies is less standardised than in the USA, similar trends can be identified operating from somewhat later dates.

\section{Occurrence of an Event}

The use of "occurrence" instead of "accident" has given rise to its own problems of interpretation, especially in the last fifteen years or so. Although insurers have been prepared to accept liability for human error which causes damage over a period of time, they have continued to be anxious to avoid liability for damage caused by ordinary wear and tear or by the progression of natural causes. ${ }^{10}$ As in the case of "accident," an event has been described as "something which happens at a particular time, at a particular place, in a particular way" even if it is not sudden. ${ }^{11}$ Continued unidentified incidents may then not give rise to an "event" or an "occurrence" which triggers liability under the policy. But again the interpretation of these words varies, and it can be hard to draw the dividing lines.

The practical importance of the distinctions relating to "occurrence" can be illustrated as follows:

- An "occurrence" may be needed to trigger any liability under the policy at all.

- A policy commonly will limit liability to a maximum sum per occurrence. If then there is only one occurrence but there are multiple losses, the insurer's exposure is limited. By contrast, if there is more than one occurrence, the insurer's liability is multiplied.

- A policy will often be subject to a deductible so as not to cover the initial amount of the claim. Again this limit will apply per occurrence, and the insurer's liability may then be reduced if there are multiple occurrences each with its own deductible (see Question 37 infra no. 30). The legality of a deductible is affected by whether the insurance protects only liability to a third party and is in an area where it has been made compulsory by legislation. The legislation then requires the policyholder to have either unlimited cover or cover up to a set sum. Within this legislative framework no possibility of a deductible exists at present.

- Apart from the maximum sum per occurrence, a policy might also be subject to an aggregate limit for all claims so that the insurer is protected no matter how many occurrences are involved (see infra no. 33). Similarly claims series clauses in effect may treat independent damage events as if they were a single event (see infra no. 43).

9 M. Clarke, Liability Insurance on Pollution Damage [1994] J Business Law 545.

${ }^{10}$ Lloyd LJ in Schiffshypothekenbank Zu Luebeck AG v Compton (The Alexion Hope) [1988] 1 Lloyd's Rep 311.

${ }_{11}$ AXA Reinsurance(UK) v Field [1996] 2 Lloyd's Rep 233. 
17 If more than one occurrence is found, it may therefore benefit either insurer or insured, depending upon the particular facts. It could be in the interest of either party to argue in favour of multiple occurrences. For example:

- If an insured has a policy limit of a maximum sum of $£ 1$ million per occurrence with a deductible of $£ 100,000$ and there is no aggregate limit, the insured gains up to $£ 900,000$ for each additional occurrence.

- If the insured's policy also has an aggregate limit of $£ 10$ million, the insured will benefit from each additional $£ 1$ million occurrence up to and including ten occurrences.

- However, for every occurrence up to the aggregate limit the insured's recovery will also be reduced by the amount of the deductible of $£ 100,000$, and there can be no recovery beyond the aggregate limit of $£ 10$ million.

18 It is not only primary insurance companies and insureds that may be involved in these disputes, but also reinsurers. Indeed perhaps the most fertile ground for litigation has involved these forms of secondary insurance and the treaties offered by reinsurance companies. A case which illustrates the practical consequences in relation to reinsurance is Caudle v Sharp. ${ }^{12}$ The Court of Appeal was faced with the question of whether losses could be aggregated under a reinsurance treaty because of one single "event," or whether there were several events, in which case reinsurance would be curtailed because it applied only to liability for losses exceeding prescribed limits in respect of one event. The reinsured argued that a managing agent, who had placed individuals on a loss-making syndicate at Lloyd's, had a "blind spot" in failing adequately to research and investigate asbestos risks. This failure, it was argued, constituted the "event" that had led to losses arising from asbestos-related claims set up under 32 reinsurance contracts. In contrast, the reinsurer argued that entry to each of the 32 contracts was the "event" and that it could not therefore be liable for the aggregate losses.

19 The Court found in favour of the reinsurer, concluding that the agent's "blind spot" was not an "event" unless he acted upon it, so that there were 32 events rather than one. To be a single event the losses had to be bound together by a common factor other than there having been a series of similar occurrences or losses. An event was held to have three components:

- there must be a common factor that can properly be described as an event (it must be limited in time and space); and

- it must satisfy a test of causation (the event must be capable of producing legally relevant consequences); and

- it must not be too remote in the circumstances (so that realistically it must be the kind of event that the parties to the contract contemplated).

12 [1995] LRLR. 433. 
The Unities of Time, Place and Cause

As the above case of Caudle $v$ Sharp indicates, whether a court finds an occurrence or event, as opposed to a series of incidents, depends upon the unities of time, place and cause. These factors were clearly laid out by the arbitrator in a decision of much persuasive authority, known as the Dawson's Field arbitration: ${ }^{13}$

“An 'occurrence' ... is not the same as a loss, for one occurrence may embrace a plurality of losses. Nevertheless, the losses' circumstances must be scrutinised to see whether they involve a degree of unity to justify their being described as, or as arising out of, one occurrence..... In assessing the degree of unity regard may be had to such factors as cause, locality and time and the intentions of human agents."

The arbitration arose out of the hijacking by Palestinian terrorists of four aircraft from different locations on a single day in 1970. Three of the four planes were flown to an airstrip in Jordan while the fourth was flown to Cairo. All four aircraft were later blown up by the terrorists. The issue was whether the destruction of the three aircraft in Jordan was the result of one occurrence or three. This was the key to an excess of loss reinsurance contract that covered "each and every loss ... and/or occurrence and/or series of occurrences arising out of one event." The arbitrator decided that the destruction of the three aeroplanes constituted one event. This was because the aircraft were destroyed "in close proximity more or less simultaneously, within the time span of a few minutes, and as a result of a single decision to do so." However, if the aircraft had been destroyed when hijacked, the arbitrator indicated that he would have found separate occurrences because, even though there was a common purpose behind the hijacking, the aircraft had been taken by different people from very different places. The arbitrator rejected the argument that there was a single event simply because there had been an overall plan. The terrorist plan by itself could not constitute an event, but the common purpose when allied to the unities of time and place were the reasons for finding only one event and not three.

The Dawson's Field arbitration was the key authority relied upon in the later case of Kuwait Airways Corporation v Kuwait Insurance Co. ${ }^{14}$ The claim in this case was for the loss of fifteen aircraft which had been seized at Kuwait airport after that country had been invaded by Iraq in 1990. They were flown to Iraq and incorporated into the fleet of that country. The loss of all the planes owned by Kuwait Airways occurred at the same time and place, and each was lost as a result of the invasion by the forces of Saddam Hussein. The decision is thus similar to that reached in Dawson's Field.

${ }^{13}$ Rix J in Kuwait Airways Corporation v Kuwait Insurance Company [1996] 1 Lloyd's Rep 664 citing Michel Kerr QC in the unreported arbitration case, Dawson's Field 29 March 1972.

14 [1996] 1 Lloyd's Rep 664. 
23 However, these two cases contrast with the findings made in relation to another case concerning an aircraft seized during the occupation of Kuwait. In Scott $v$ Copenhagen Reinsurance $\mathrm{Co}^{15}$ a plane belonging to British Airways was seized at the same time as the others in Kuwait. However, unlike the others, it was not flown to Iraq but instead remained at the airport. It was not destroyed until some months later when it was bombed during the attempt to liberate the country. This loss was held not to arise out of the same event that had led to the claim for the other aircraft. Although there was unity of place, there was a time difference involved and the effective legal cause of loss was not the seizure of the airport, but the liberation of it. The concept of aggregation of loss required a significant causal link between the events in question and a single unifying event. In this case there was not a sufficient causal link between the plurality of aircraft losses for them to constitute a single aggregated claim. As a result the primary loss insurers were unable to add the British Airways plane to their claim against a reinsurer under the terms of their excess of loss policy covering one event.

24 In another example, the lack of unity in both time and place proved crucial in denying that there was one occurrence where, following riots in Indonesia preceding the resignation of President Suharto, damage was caused to 21 of the 67 shops owned by the same company. The damage was found to result from several occurrences because it took place over two days and in different locations spread over some thirty miles. ${ }^{16}$ A single occurrence could not be found just because there was a common underlying cause or because there was a common intent or purpose involved.

25 These cases illustrate that fine lines must be drawn. How long must be the separation in time for the damage to be regarded as the result of more than one occurrence? What distance is required between the sites where damage occurs in order for a separate occurrence to be found? What exactly constitutes a common purpose? How are "effective" legal causes of loss to be identified and distinguished from other factors which are held not to be legally relevant? No clear answers can be given to these questions because each case must be decided on its particular facts. As the first instance judge stated in Scott: ${ }^{17}$

"I have been referred to a number of authorities. In a real sense I think the question is one of impression which does not bear too much analysis."

26 Even though there is no bright line rule which can be easily applied, the above principles can be used to help to resolve the hypothetical problems posed in the Questionnaire.

\footnotetext{
${ }^{15}$ [2003] Lloyd's Law Reports Insurance and Reinsurance (Lloyd's Rep IR) 696.

${ }^{16}$ DP Mann v Lexington Insurance Co [2001] Lloyd's Rep 1.

17 [2003] 2 Commercial Law Cases (CLC) 431 at 457.
} 
36. CASE STUDY (building insurance and insurance cap) $P$ is the owner of factory premises consisting of several buildings which he has insured against harm resulting from severe weather conditions. The insurer's liability is capped at $€ 500,000$ per damage event. During a thunderstorm that lasts several hours, two of the buildings are struck by lightning and both are completely burnt down. Each of the buildings was worth $€ 300,000$. What is the insurer's obligation to pay for the damage under the policy?

Where premises are insured for a maximum sum, what is to happen after a storm lasting several hours causes damage in excess of the overall limit when two separate lightning strikes hit two of the buildings? Applying the above tests, it is likely that the insurer would be able to limit its liability by reference to the $£ 500,000$ maximum sum insured, although this would depend upon the specific words used in policy. The reason for this is that the damage occurs over a short period of time, at the same general locality (albeit to separate buildings), and it is caused by the same type of natural event. The unities of time, place and cause thus appear to be satisfied. This leads to the conclusion that there is only one event which has caused the loss, and that the limit to the insurer's liability is effective.

There is some analogy here with the litigation that took place following the terrorist strike and the subsequent collapse of the twin towers of the World Trade Center in New York in 2001. ${ }^{18}$ There is some UK authority for seeing the destruction caused by the two aircraft striking two separate buildings within eighteen minutes of one another as being caused by one event, albeit separate from the similar attack on the same day on the Pentagon in Washington. ${ }^{19}$ However, there is also some USA authority which runs counter to such an analysis: in a much older case two adjacent walls collapsed 50 minutes apart, and were held to have done so as a result of two "accidents" even though both of these had been caused by the same storm. ${ }^{20}$ A division in analysis is also to be found in the USA decisions concerning the events of $9 / 11$. In relation to insurance policies that contained a definition of "occurrence" one court found that the collapse of the two buildings constituted a single occurrence. ${ }^{21}$ By contrast, after a trial involving those policies that did not define what amounted to an "occurrence," a jury held that the collapse of the two buildings constituted two occurrences.

However, an important qualification must be added to the above analysis: the solution to such problems depends upon the precise wording of the insurance

${ }_{18}$ M.S. Moore, The Destruction of the World Trade Center and the Law on Event-Identity, in: J. Hyman/H. Steward (eds.), Action and Agency (2004).

19 P \& C Insurance Ltd v Silversea Cruises [2004] Lloyd's Rep IR 696.

${ }^{20}$ Arthur A Johnson Corp v Indemnity Co, 164 North Eastern Reporter, Second Series (NE2d) 704 (1959).

${ }^{21}$ SR International Business Insurance Co, Ltd v World Trade Center Properties LL, 222 Federal Supplement, Second Series (F.Supp.2d) 385 (S.D.N.Y. 2002), affirmed by World Trade Center Properties LLC v Hartford Fire Insurance Co 345 Federal Reporter Third Series (F.3d) 154 (2d Cir. 2003). 
contract. For example, the use of "originating cause" rather than "event" or "occurrence" has been held to be much less restrictive and to encompass a continuing state of affairs or the absence of something happening. ${ }^{22}$ See also infra no. 33 .

37. In your national legal system, have the courts developed general principles that address the issue of whether a damage event is considered to be a single incident, in which case the insured has to bear any stipulated deductible only once, or a plurality of several independent losses, in which case the deductible applies to each, leaving the insured to bear the amount several times? Alternatively, is this issue addressed by standard clauses used in contracts of insurance? If third-party insurance is required by law, would this have any effect on the legality of a deductible?

30 See answer to Question 35 supra no. $5 \mathrm{ff}$.

38. CASE Study (auditors' liability) $P$, an independent auditor engaged by $X$ Ltd to certify its accounts, is asked by X Ltd to meet with two potential investors in the company, $A$ and $B$. At the meeting, $P$ vouches for the company's financial well-being. In consequence, $A$ and $B$ make large purchases of shares in X Ltd. It transpires that P negligently misrepresented the value of the company to the investors. A and B consequently suffer economic losses which they seek to recover as damages from $P$. In principle, their losses are covered by $P$ 's professional indemnity insurance, but according to the terms of the policy the insured has to bear a deductible of $€$ 5,000 per damage event. In the instant case, does $P$ have to bear the deductible amount only once or with regards to both claims?

31 The insurer could argue on the basis of Caudle $v$ Sharp that, although the negligent advice was the single cause of the losses, each investment was a separate occurrence and two deductibles should be applied to the claim. However, this is the less likely solution for it is the insured who appears to have the stronger case: the advice was given on one occasion and was thus limited in time and space; the advice was the clear cause of loss; and it was not too remote because all the parties anticipated that investment would result from the advice given. There is a unity of time, place and cause and it is therefore likely that only one deductible would be applied and only one occurrence found.

32 As in the answer to Question 36 (supra no. $27 \mathrm{ff}$.), it is necessary to add the qualification that the correct approach to such cases depends on the precise wording of the insurance contract. See further supra no. 29.

${ }^{22}$ Axa Reinsurance (UK) v Field [1996] 1 Weekly Law Reports (WLR) 1026. 
B. Other Limits on the Amount of Cover

1. Aggregate limit clauses

39. In your country, do standard-term insurance policies use aggregate limit clauses whereby the liability of the insurer is capped by a maximum amount per specified period? If so, please give examples of how these clauses are worded and how they are interpreted, paying particular regard to the issue of whether a damage event is considered to be a single indivisible loss (therefore falling into only one period) or a plurality of losses (potentially falling into several different periods).

Aggregate limit clauses are used in respect of United Kingdom risks, but, as previously mentioned, there are no standard-form words in universal use, so everything turns on the wording of the individual policy. In this context, it should be noted that one leading work, in particular, emphasises the dangers of embarking upon too general a discussion of the issues: ${ }^{23}$

“... different aggregation clauses employ different language. It is important not to try and impose upon any particular aggregation clause a preconception that the particular claims should or should not be aggregated - but instead to give effect to the language used. Any attempt to identify and then impose a single, coherent philosophy of aggregation would inevitably be insensitive to differences in policy wording and accordingly doomed to failure."

\section{Claims series clauses}

40. In your country, do standard-term insurance policies use claims series clauses whereby several independent damage events are treated as a single damage event (a single series) which is subject to a single liability cap? If so, please give examples of how these clauses are worded and how they are interpreted. Please state in particular what criteria are used for distinguishing between several independent damage events and a single damage series.

Claims series clauses may treat independent damage events as if they were a single event. As previously mentioned, however, there are no standard-form words universally used in insurance policies for United Kingdom risks, so everything turns on the wording of the individual policy.

${ }^{23}$ J.L. Powell/R. Stewart (eds.), Jackson and Powell on Professional Liability (6th ed. 2007) para. 8-096. 


\section{Long tail damage}

41. In your country, do standard-term insurance policies use clauses whereby the liability of a former insurer is limited to a specified period of time after the end of the insurance contract? If so, please give examples of how these clauses are worded and how they are interpreted. What is considered to be the starting point for the relevant limitation period (e.g. the date on which the insurance contract ended, the date of the insured's negligence or the date on which the damage was sustained)? In this context, where is the line drawn between several independent damage events and a single damage event?

35 As previously mentioned, there are no standard-form words universally used in insurance policies for United Kingdom risks. In brief, the answers to these questions are that such clauses are used, albeit with varying wording; that the "starting point" for liability under the policy depends upon the particular clause used and upon the court's interpretation of it; and that the general principles which have been described above are again used to distinguish several events from single occurrences. However, it is with regard to the "starting point" for coverage that courts have encountered acute difficulty. This requires extensive discussion of the principles which the courts have developed.

36 When the event or occurrence that triggers the liability of the insurer has been identified, it must then be determined whether it falls within the period of cover. The causal date is all important. The answer is usually easy to provide in cases involving accidents because the exact point in time when the sudden event occurs is generally easy to identify; the time and place when cars collide will be known. However, where an accident is not involved and the loss occurs gradually, especially if the damage remains undiscoverable for many years, it can be much more difficult to decide whether there is insurance coverage. There have therefore been particular problems with claims for cancer or asbestos-related disease,${ }^{24}$ and issues have also been widely litigated in relation to product and environmental liability and, to a lesser extent, in relation to the liability of professionals.

37 Decisions again vary according to the precise words used in the particular insurance contract, and much uncertainty results. For example, an injury "caused" during a period of insurance has been held to include the time from when the claimant was first exposed to the substance that later caused damage. However, policies written to cover diseases or injuries "occurring" or "sustained" or "contracted" may be more limited, and confined to the later time when injury to the claimant actually took place.

\footnotetext{
${ }^{24}$ For discussion in relation to asbestos see C. Lahnstein, D. Maranger and N. Roenneberg's paper in: Munich Re Group (ed.), 7th International Liability Forum (2003).
} 


\section{The Three Triggers}

Broadly, there are three possible triggers and four different rules which courts may use to fix the point at which insurance coverage may arise. Until recently it was very uncertain which of these rules would be adopted by a court in the UK. Although there is now Court of Appeal support for the second of them - being that favoured in the USA ${ }^{25}$ - the position remains uncertain. This is because further crucial litigation is presently taking place, and a High Court decision is imminent. ${ }^{26}$ In outline, in chronological order, the four possible rules are:

\section{a) Exposure.}

The trigger here is when exposure occurs to the activity or circumstance which gives rise to the action. Because exposure is often a continuous process and may occur over a long period of time, there may be several insurers and a number of policies applicable to the loss. Recently in Bolton MBC v Municipal Mutual Insurance Ltd the Court of Appeal rejected the exposure theory. ${ }^{27}$ This was because the insurance policy indemnified against liability and, at the stage of exposure, there was no liability because the victim had yet to suffer a personal injury. In the absence of injury there could be no liability and therefore no insurance relevant. According to Longmore $\mathrm{LJ}^{.28}$

"It is inconsistent with principle because the contract between the parties is an agreement to indemnify against liability. It cannot be right that, at the stage of initial exposure or initial bodily reaction to such exposure, there could be a liability on the part of Bolton in respect of which they could require to be indemnified under any public liability insurance policy."

b) Injury in fact.

The trigger here may be later than when exposure took place because it begins when the damage actually occurs, even if the damage is not yet apparent and cannot be discovered. This means that it may be difficult to identify not only whether an injury has yet occurred, but also the exact point in time when it does so. These problems are especially acute in asbestos related disease cases. For example, even if pleural plaques are found in the lungs, the court has determined that an injury may not have been suffered. ${ }^{29}$ In the above case involving

25 V. Fogelman, Environmental Liabilities and Insurance in England and the United States (2005) para. 30.25.5.3 and R. Merkin, Reinsurance Law para. C.2.2-25.

26 Six test cases collectively known as the "Employer Liability Policy Trigger Litigation" were heard before Burton J in June 2008 in a hearing scheduled to last nine weeks. The lead case is Municipal Mutual Insurance v Zurich Insurance Co. At the time of writing the result of the litigation is not known.

27 [2006] 1 WLR 1492.

${ }^{28}$ [2006] 1 WLR 1492 at para. 15

29 Rothwell v Chemical \& Insulating Co Ltd [2007] United Kingdom House of Lords (UKHL) 39, [2007] 3 WLR 876 noted by K. Oliphant in: H Koziol/B.C. Steininger (eds.), European Tort Law 2006 (2008) at 155. 
Bolton $M B C$ the injury in fact rule received much support from the Court of Appeal when it decided that the insurer's liability to indemnify was triggered when cell mutation began. This was about ten years before there were any symptoms of the disease mesothelioma; and potentially it was decades after the date of exposure to asbestos itself. Although likely to be more restrictive than the exposure rule, the injury in fact trigger similarly may spread liability among a number of insurers. This is especially the case where there is gradual pollution damage for it has been accepted that the injury may be progressive and continuous over a period of time and it may thus spread liability over several policy periods.

c) Manifestation.

41 Adopting this rule would mean that there is no occurrence until the later time of when the injury becomes apparent. ${ }^{30}$ This reduces insurer liability by concentrating cover only upon those relatively recent policies which are in force when the injuries reveal themselves. Claims can even be concentrated into one policy year. In addition, this makes it very difficult, for example, for those working with asbestos to obtain any insurance cover at all. This is because new insurers are reluctant to assume liability for the past exposures. In fact, once the disease has been diagnosed, existing insurers are likely to cancel or not renew their policies in order to limit their liability to the existing claims and thus avoid future manifestations of injury. This can be a disaster for later claimants because they may find that they are suing an organisation that is worthless. On the other hand, the manifestation rule can be more favourable to claimants in one respect: for the purpose of limitation of actions (by which a time is set within which claims must be brought), the manifestation rule allows claims to be made later than under either the exposure or the injury in fact rules.

d) Tripple trigger.

42 This is the broadest trigger for coverage. It was first developed in the USA in relation to asbestos claims, and offers a choice of any of the three alternatives listed above. ${ }^{31}$ That is, it fixes liability on any insurer whose policy was in force (i) at the time of initial exposure, or (ii) during continued exposure, or (iii) at the time of manifestation. This rule is therefore likely to draw a number of insurers into the liability net. However, the approach was recently rejected on the specific facts of the Bolton case because the Court could see no need for such a broad approach: the policy reasons in favour of compensation which applied in the USA in relation to the much greater number of asbestos disease claimants were thought not to apply in the UK. Even after the Bolton case much uncertainty remains. Hobhouse LJ was keen to limit the effect of his judgment: ${ }^{32}$

${ }^{30}$ Eagle-Pitcher Industries v Liberty Mutual Insurance Co 682 F.2d 12 (1982).

31 Keene Corporation v Insurance Co of North America 667 F.2d 1034 (DC Cir 1981), cert denied 455 US 1007 (1982).

32 Bolton v MBC Mutual Insurance Ltd [2006] 1 WLR 1492 at 1505 para. 24. 
"I am far from saying that what has been called this multiple trigger or, sometimes, triple trigger theory (exposure, development of disease, and diagnosis) might not be held, on some future occasion, to be appropriate for employers' liability policies in general, depending on the precise words used. But, as far as public liability policies are concerned with the specific wording used in the present cases, I see no need for the English courts to adopt the multiple trigger theory. It has been adopted in the United States avowedly for policy reasons in relation to the vastly greater numbers of asbestos-disease sufferers in that country. I see no reason to adopt it in this particular case where the same policy considerations are not present."

We must therefore await the results of the current litigation to discover whether there will be any more certainty with regard to which trigger is to be applicable. However, the prospect arises of there being gaps in insurance coverage, with the result that claimants will then be uncompensated.

\section{Apportionment between insurers}

No matter what the trigger, if several insurers are involved there can be difficulties in apportioning liability among them. There are various possibilities. For example, the insurers could each be held jointly and severally liable up to their policy limits. Alternatively, they could be held responsible only for a share of the damage based on the different lengths of time they were on risk, or according to the different limits in the respective policies. In Barker $v$ Corus $^{33}$ the House of Lords held that the insurers were not liable in full for the damage caused but only to the extent of the probability that the employer they insured had caused the asbestos-related injury. This could have led to substantial under-compensation of those who had worked for several employers and who, for a variety of reasons, could not sue or enforce a judgment against one or more of them. As a result, the decision led to considerable protest from claimants, their trade unions and their lawyers. The Government immediately took action. For asbestos cases alone involving the disease mesothelioma, the Lords decision was effectively reversed by the Compensation Act 2006, sec. 3 which makes defendants liable jointly and severally for the whole of the damage. Asbestos claimants thus gain full compensation even if only one of the former employers has insurance coverage. However, apart from these asbestos cases, the proportionate damages approach adopted by the Law Lords in Barker remains good law.

\section{Claims-made policies}

Because of the possible confusion caused by these various theories of when an "occurrence" triggers liability under a policy, the London insurance market introduced a new form of words into policies in the 1980s. Rather than

${ }^{33}$ [2006] UKHL 20, [2006] 2 AC 572. 
referring to occurrences, these policies base liability on when claims are made against the insured. Although there can be difficulties in defining the meaning of "claim," liability here is much more certain. Insurers are attracted to such policies because they are able to close their books at the end of the year and they have no need to fear a "long tail" liability. This wording has been increasingly used in product liability insurance and, for example, applies to nearly all policies taken out by pharmaceutical companies. However, it has been attacked in other countries with some vigour, and in France there was an attempt to make "claims-made" policies illegal for certain types of insurance. ${ }^{34}$ However, the severe restrictions imposed by the Cour de cassation in 1990 were eased in $2003 .^{35}$

42. Case Study (long tail damage) P Company develops, manufactures and distributes motor equipment, including fuel pumps. As the result of a design fault in the pumps, the fuel supply of motor vehicles in which they are incorporated is often interrupted without warning. Assume that this leads to numerous accidents for which P Company is liable under your laws on product liability. Until a) the pump's development, b) its manufacture, c) its distribution, and d) the consequent accidents, $P$ Company's product liability was insured by I. After the termination of the insurance contract with I, P Company takes out insurance with J. Which insurer, I or J, has to cover P Company's liability for its faulty fuel pumps in each of scenarios a)-d)? Assume that the standard terms of both insurers' contracts contain clauses on liability for long tail damage that are most common in your country.

46 The change in policy wording described above (supra no. 45) helps to answer this question. When a policy has been issued on claims-based liability that liability is triggered only by the claims resulting from the accidents themselves in (d) and not by the earlier periods of risk-creating activity in (a) - (c).${ }^{36}$ What constitutes a claim for this purpose, and when a claim has been made or received, has also been the subject of litigation. ${ }^{37}$

47 However, having found more certainty in a particular phrase, insurers have then made matters more complicated by arranging for the phrase to be superseded by extensions and revisions to policies. We have already seen the complications that resulted when the word "accident" was revised to "occurrence" to accommodate the demands of the market for cover for damage occurring gradually. Similarly, claims-made policies have also been extended to offer much wider cover. Insureds can protect themselves against claims arising after a policy terminates in two ways. They can obtain "prior acts" coverage under

${ }^{34}$ M.A. Clarke, The Law of Insurance Contracts (5th ed. 2006) para. 17-4B.

${ }^{35}$ M. Schubert, Coverage Triggers in French Liability Insurance, (2003/July) Insurance Law Monthly. See further S. Galand-Carval, Aggregation and Divisibility of Damage in France: Tort Law and Insurance (contained in this volume) no. $92 \mathrm{ff}$. and 99.

${ }^{36}$ Tioixide Europe Ltd v CGU International Insurance plc [2005] Lloyd's Rep IR 114, affirmed [2006] Lloyd's Rep IR 31.

${ }_{37}$ Clarke (fn. 34) para. 17-4D. 
which the new insurer charges an additional premium to cover for events occurring before the beginning of the new policy. Another option is to purchase an extended reporting period, or "tail" coverage from the old insurer. This covers future claims made for incidents occurring during the time of the claimsmade coverage. In effect, it converts claims-made into occurrence coverage. It then gives rise to problems, highlighted above, concerning what is to be the effective date of the occurrence which triggers liability under the policy.

\section{Liability limits in compulsory third-party insurance}

43. Would the fact that, in certain fields, third-party insurance is required by law have any effect on the extent to which liability limits in terms of aggregate series clauses, claims series clauses and long tail damage clauses are legally allowed?

This depends upon the wording of the statute imposing compulsory insurance. In road traffic insurance, for example, the cover that is required is without limit. Therefore aggregate clauses which imposed an upper limit on liability would not meet the statutory requirements, and those who took out policies with such limits would be committing criminal offences. In contrast, however, insurance against employer's liability is only required up to a stated maximum sum. In such a circumstance any limits which confined liability to that maximum figure would be acceptable.

\section{Conclusion}

There is much uncertainty about both the law and practice in relation to insurance aspects of the divisibility of damage. The lack of empirical research of insurers' practices makes it difficult to assess how claims are assessed initially and how disputes are actually treated by insurers. Furthermore, the diversity of insurance policies makes it difficult to formulate general statements about the law: much depends upon the particular policy wording and the specific circumstances of the claim. There are no standard form policies for United Kingdom risks.

Perhaps because of this uncertainty there is a growing body of case law in this area. It is clear that more disputes are now reaching court. There is an increasing sophistication in the analysis of causal factors relevant to loss. This may be driven in part by increasing scientific understanding of the complexity of the material world, and a psychological recognition that simplistic accounts will not suffice. This adds to the readiness of the parties to contest ultimate responsibility for the loss, and it fuels refined judicial analysis of the facts giving rise to the dispute.

Insurers have continued to revise their policies in order to combat increasing exposure to liability as a result of recognition of these wider causal factors. Clauses have been added and liability defined in more and more detail in an at- 
tempt to preclude certain possibilities. In particular, there has been concern to avoid liability for injuries which occur gradually over a period of time. However, in demanding that damage must result from specific events, such as an accident or occurrence, policies have proved to be unduly restrictive. Market forces have then led to a relaxation in the wording of some policies. In addition, social and other factors favouring insurance coverage have encouraged courts, especially in the USA, to interpret policies in favour of claimants. The overall picture is therefore a complex one.

52 It is apparent that most of the major issues confronting the UK courts have been litigated previously and more extensively in the USA. Although the USA cases favouring insurance coverage have not always been followed by courts in the UK, they have had an influence. It is true that the American market is significantly different from that in the UK. In particular, it makes more extensive use of standard form policies, and there are very different factors affecting insurances - such as those covering environmental pollution and product liability - which lie at the heart of the divisibility of damage debates. In particular, it is noteworthy that there have been no concerns over asbestos litigation in Germany, for example, because such diseases are not compensated within the tort system but as part of social insurance. Liability insurance issues do not then arise. However, for a variety of reasons American policy wording is increasingly making its way to Europe, and the nature of disputes (if not always their outcome) is broadly similar. This does not make these disputes easier to solve, but by looking across the Atlantic we might be better prepared to see what is coming.

53 Here it is suggested that European insurers have been slow to react to these changes of wording to deal with multiple causation issues, and as a result have become exposed to a wider time range within which liabilities may be established. If this is the case, insurers should pay close attention to aggregation and divisibility issues. Policies can, and should, be amended to ensure that the extent of the risk matches that which was intended when the premiums were first set. Of course, this basic objective is pursued by every underwriter on a day to day basis. It is all too easy to state and is always much harder to implement in practice. Issues regarding aggregation and divisibility of damage will continue to grow in importance in insurance and tort law for some time to come. This is because of the central importance of insurance to this area of civil litigation. It is the driving force - the "lifeblood" - of the tort system. Without it, in many cases, damages would not be paid and cases would simply not be litigated. We would live in a very different legal world. ${ }^{38}$

${ }^{38}$ See supra fn. 1. 